\title{
¿Por qué el pasado nos convoca como colectiva de mujeres?
}

\section{Why does the past convoke us as a collective of women?}

\author{
doi.org/10.48162/rev.46.006 \\ Verónica I. Williams* (iD) orcid.org/0000-0003-4194-5214 \\ Alejandra Korstanje ${ }^{\dagger}$ (i) orcid.org/0000-0001-6150-3005
}

\section{RESUMEN}

El devenir académico de la arqueología en Argentina tiene ya una importante trayectoria y no ha sido ajena a los vaivenes políticos, ideológicos y de políticas públicas. La equidad de género y la necesidad de las mujeres de pensarse en sus condiciones y contextos de trabajo es un reclamo de nuestros tiempos. Son escasas las arqueólogas que en los últimos 50 años del siglo XX han llegado a ocupar altos cargos de gestión y han formado varias discípulas. Conocer cómo eran sus condiciones de producción en sus inicios y preguntarnos cómo fue la transmisión de conocimientos de mujeres a mujeres es un requisito para poder construir no solo historiografías y genealogías, sino para comprender nuestras propias construcciones como científicas y universitarias. Presentamos la génesis de los encuentros de mujeres arqueólogas del noroeste argentino vinculadas entre sí por una genealogía de aprendizaje que parte de tres pioneras desde la década de 1960, Ana María Lorandi, Myriam N. Tarragó y Marta Ottonello, con el fin de registrar una historia como un relato cronológico, analítico y valorativo resultado de la suma de una serie de narraciones de las experiencias de las protagonistas.

Palabras clave: arqueólogas, historiografía, condiciones de producción en ciencia

\section{ABSTRACT}

The academic development of archaeology in Argentina has a significant history and has been affected by political, ideological, and public policy ups and downs. The times demand that

\footnotetext{
* Instituto de las Culturas, Universidad de Buenos Aires. Consejo Nacional de Investigaciones Científicas y Técnicas.veronicaw33@gmail.com

† Instituto de Arqueología y Museo, Facultad de Ciencias Naturales. Instituto Superior de Estudios Sociales, Universidad Nacional de Tucumán. Consejo Nacional de Investigaciones Científicas y Técnicas. alek@webmail.unt.edu.ar
} 
women re-think gender equity and their working conditions. In the last fifty years of the twentieth century, only a few women archaeologists reached high management positions or trained female students. We need to know what their conditions of production were like in the beginning and asking ourselves how knowledge was transmitted from woman to woman in order to construct not only historiographies and genealogies, but also to understand our own constructions as female scientists and academics. We present the genesis of the meetings of women archaeologists working in northwestern Argentina, tied together by a genealogy of learning that started with three pioneers in the 1960s: Ana María Lorandi, Myriam N. Tarragó, and Marta Ottonello, in order to record this history as a chronological, analytical, and evaluative account, resulting from the sum of a series of narratives of the experiences of the protagonists.

Keywords: female archaeologists, historiography, production conditions in science

Recibido: $28 / 04 / 2021$

Aceptado: 04/08/2021

\section{INTRODUCCIÓN}

En estos días y en este país (y casi en este mundo) es difícil sustraerse a los debates sobre el papel y los derechos de las mujeres. Temas que antes no pensábamos, por tenerlos naturalizados quizás, ahora son cotidianos en nuestras conversaciones, cuestionando, entendiendo, comparando y, sobre todo, analizando sucesos e historias. Es un tiempo de discurrir, pero también un tiempo de actuar en conjunto.

Como sucede en la mayoría de las áreas del conocimiento científico, la arqueología y la antropología fueron dominadas por varones desde sus comienzos (Korstanje y Archila, 2020; Wylie, 2001). En Argentina, si bien contamos orgullosamente con mujeres precursoras de la práctica arqueológica -con aportes de sistematización de material cerámico del Noroeste Argentino (NOA) (Odilia Bregante, 1926); tesis doctorales de antropología física en la Universidad de Buenos Aires (Juliane Dillenius, 1913 [1911]); profesionales de disciplinas afines como participantes en campañas arqueológicas (Elena Chiozza) o ligadas a un papel de asistente dibujando o acompañando-, el liderazgo era de un varón, que podía ser un pariente cercano, marido o profesor (Elena Holmberg de Ambrosetti, Delia Millán de Palavecino, Ana Montes) (Ramundo, 2017; 2019). Es recién en la década de 1960 que empieza un claro liderazgo femenino con toda una generación local de científicas argentinas, de las que nos sentimos herederas (ej. Ana María Lorandi, Myriam Tarragó, Carlota Sempé, Susana Renard, Marta Ottonello, Chela Lanzone), que abrieron camino ocupando espacios importantes (aunque siempre muy minoritarios) tanto en lo académico como en la producción misma de conocimiento, y cuya obra es hoy reconocida, valorada y citada incluso más allá de 
nuestro país. Sin embargo -y quizás también esto esté relacionado con el quiebre institucional, social y la persecución a los y las que tenían ideas innovadoras y democratizantes realizado durante la dictadura cívico militar de la década de 1970-, es recién en la década del ochenta que comienzan a generarse cambios con explícita intención de empoderamiento de las mujeres, mediante investigaciones sobre el tema dentro de la arqueología (ej. Lazzari, 2003; Scattolin, 2003, 2006 a y b; Williams y Alberti, 2005) y la formación de nuevas generaciones de arqueólogas y arqueólogos con perspectiva de género.

En el marco de la Segunda Reunión Internacional de Teoría Arqueológica en América del Sur (Olavarría, 2000), se realizó una mesa sobre "Género y Etnicidad en la Arqueología Sudamericana”, coordinada por Benjamín Alberti y una de nosotras (VW). Expusieron nueve participantes y fue la primera reunión donde, en idiomas español y portugués, se presentaron investigaciones sobre estos dos temas que se atribuían a un marco general de enfoque post-procesual, aunque este rótulo no tenga un significado bien definido. Sin embargo, puede decirse que ambas líneas de investigación (género y etnicidad) también desde las identidades de las periferias político-teóricas representan, en sus manifestaciones actuales, reacciones contra el procesualismo de la Nueva Arqueología (Alberti y Williams, 2005: 7). La falta de trabajos publicados por arqueólogos/as sudamericanos/as sobre el tema de género parecería ser, a primera vista, un ejemplo de la necesidad de la arqueología de la región de competir con los países centrales en cuanto al desarrollo de nueva teoría. No obstante, la situación es en realidad más compleja y tiene que ver con diferentes causas dentro de las historias particulares de los países sudamericanos alrededor de los temas de la lucha de mujeres, los movimientos nacionalistas y los vínculos con países europeos o norteamericanos y su influencia histórica (Korstanje y Archila, 2020; Navarrete, 2010). Si bien no se puede generalizar para todos los países sudamericanos, existiría una tendencia en los países con movimientos nacionalistas fuertes a invisibilizar el papel de la mujer (Alberti y Williams, 2005: 9).

Al respecto, en 2005, una de nosotras (MAK), al comentar un artículo de Margaret Conkey (2005) sobre las intersecciones de la arqueología indígena y el feminismo, llamaba la atención sobre el escaso impacto del feminismo en la arqueología argentina, en tanto que las Arqueologías Indígenas ${ }^{1}$ tenían más oportunidades de trascender, debido a que surgían como una necesidad interna de las comunidades por diferenciarse y diferenciar su conocimiento de la ciencia, y así oponerse a la hegemonía occidental y cristiana. Notaba que en aquel entonces la agenda de género estaba fuertemente marcada por las corrientes anglosajonas, e incluso, por el incentivo de becas y subsidios internacionales para el estudio del 
tema, pero aún con muy poca repercusión en el medio en ausencia de una propia agenda local de género (Korstanje, 2005).

La historia de las mujeres, como individuas empoderadas, empieza a aparecer con claridad en ciertas publicaciones, documentales, entrevistas (ej. el ciclo de encuentros "Trayectorias" ${ }^{2}$ ), pero, en tanto no fueron realizadas con perspectiva de género, ahora buscamos ir más allá y pensar la historia colectiva de nosotras. Historias de las mujeres arqueólogas, desde las prácticas mismas e historias de vidas generales; no solo de las exitosas, sino también de las menos visibles, pero, aun así, poderosas. En síntesis, bregamos por la construcción colectiva de la ciencia desde la mirada de género.

Ciencia y género son categorías construidas social y culturalmente y ambas están condicionadas por los procesos históricos que se producen en una sociedad dada. Como han manifestado Bellelli et al. (1993), la relación entre ambas puede estudiarse desde dos perspectivas: 1) desde un punto de vista epistemológico, es decir cómo se refleja la categoría género, instaurada socialmente, en la construcción y producción del conocimiento científico (Conkey y Spector, 1984) y, 2) desde la manera como esta misma categoría se evidencia en la práctica científica (Bellelli et al. 1993; Gero, 1994, 1996). En este trabajo, tomamos ambas perspectivas presentando la génesis y el desarrollo de una serie de encuentros denominados "El pasado nos convoca", sobre trayectorias personales de arqueólogas y desarrollo profesional en contextos patriarcales. El objetivo de estos encuentros fue compartir experiencias sobre nuestras formaciones académicas, prácticas en el campo y docencia universitaria (Korstanje, 2019).

A su vez, desde dos arqueologías alternativas, tales como la feminista y la indígena, Conkey planteó dos dimensiones de la interpretación arqueológica: 1) el lugar y el papel de "la experiencia", y 2) el uso de las narraciones de cuentos y las tradiciones orales (Conkey, 2005). Ambas perspectivas mostraron ser muy pertinentes cuando comenzamos a indagar en un "nosotras" como mujeres profesionales que buscan entender cómo jugaron las cuestiones de género en las trayectorias profesionales. Y ambas son importantes para lo que este artículo representa y pretende contar.

\section{CÓMO SURGE LA IDEA DE LOS ENCUENTROS}

Cuando pensamos en este formato de encuentros, que llamamos "El pasado nos convoca”, estábamos precisamente en una campaña, recorriendo distintos sitios arqueológicos de Salta y Catamarca (2016). Éramos cuatro mujeres, dos de ellas muy jóvenes, que íbamos en una camioneta propia por caminos y huellas que 
resultaron más peligrosas de lo esperado; sorteábamos también varias dificultades sociales y económicas y, casi siempre, sin señal de celular. Algo nos habrá evocado esa imagen de que éramos mujeres haciendo tareas que en otro tiempo hubieran requerido al menos de la compañía de varones, porque nos hizo empezar a reflexionar mientras caminábamos entre los diferentes sitios. Allí tuvimos algunas certezas: primero, que algo diferente había en nuestra forma de trabajar y que había arqueólogas formadas por mujeres y directoras de equipos donde preponderan las mujeres arqueólogas; y segundo, que las historias que teníamos para compartir eran maravillosas y sorprendentes, pero también duras y tristes, y seguramente estaría bueno escuchar las de otras colegas que hubieran hecho una huella profesional parecida.

Dicho esto, es notorio que "antes" no teníamos estas percepciones tan claras. Sorteábamos obstáculo tras obstáculo, pero siempre había cerca uno o más varones en los que parecía que se recostaba la responsabilidad de las campañas y de los equipos y la toma de decisiones, aunque en la realidad no fuera importante su presencia. Verónica y Alejandra, nosotras (de ahora en más Vero y Ale), estamos cercanas a la jubilación y nos conocimos como profesionales en el año 1990, cuando por ser Vero especialista en Inkas, Ale la invitó a realizar la segunda campaña a La Ciudacita (Nevados del Aconquija, Tucumán). Esa campaña también fue compleja. Subimos a pie (aunque Vero se dio cuenta de lo que se venía y se pagó una mula, digamos la verdad) desde los 400 a los 4.600 m s.n.m., cargando nuestros propios enseres, comida y mochilas. Dormimos en carpa y nevó arriba. Mucho frío y soroche. Además, el grupo de muchachos andinistas que nos hacían de guías creían que habíamos venido a una carrera de esfuerzos deportivos y no a una campaña donde debíamos observar y registrar lo más posible, así que sistemáticamente aceleraban el paso y nos dejaban atrás. Así, nos fuimos retrasando lo suficiente para que dos de las tres arqueólogas que éramos termináramos perdidas y un baqueano tuviera que salir a buscarnos en la noche lluviosa del bosque montano. Desde entonces hemos realizado juntas algunos otros viajes y campañas del estilo, en proyectos en común, en esta modalidad que después nos sorprendió descubrir (la de liderar como mujeres equipos donde se formaron muchas mujeres). Esa "ficha que nos cayó" (diríamos hoy con la claridad irremplazable del habla popular ${ }^{3}$ ) nos llevó a preguntarnos si esta situación implicaría alguna diferencia en nuestra forma de hacer arqueología respecto a otros grupos y, sabiendo que el tiempo pasa veloz para todas, decidimos reunir a otras mujeres arqueólogas en igual situación para preguntarnos, y básicamente escucharnos, sobre cómo era nuestra forma de hacer arqueología y cómo veíamos nuestras historias al respecto. 
Así tomó forma el primer encuentro, "El pasado nos convoca. Tres generaciones de mujeres en arqueología del NOA" (2017) y luego el segundo, "El pasado nos convoca. Arqueología del NOA generada por mujeres" (2019). Notar que la segunda oración o "bajada" es diferente en cada caso. Sobre el por qué de estas dos experiencias y el futuro colectivo imaginado es lo que trata este artículo.

$\mathrm{Si}$ bien nos comprometimos a escribirlo a pedido de las colegas editoras, es importante reafirmar que estos encuentros son una obra colectiva y, por lo tanto, no podemos adelantar nada de su contenido concreto sin autorización de todas las participantes. En esta ocasión, entonces, solo hablaremos de lo que fue nuestra responsabilidad inicial en cada uno de ellos: definir objetivos y organizar los encuentros, cuya sustanciación nos permitió compartir experiencias y nos llevó a comprender nuestras propias trayectorias. Como aliciente para quienes están más interesados/as en el qué, que en el cómo y el por qué, el proyecto sigue vivo y alegre. Próximamente se hará la tercera reunión, aunque esta vez se ampliará a las arqueólogas de todo el país y algunas de Sudamérica, con el propósito de finalizar una primera versión de una historia de la arqueología redactada de modo horizontal y participativo, escrita por aquellas mujeres que quieran formar parte de esta comunidad creciente.

\section{PRIMER ENCUENTRO “EL PASADO NOS CONVOCA (I). TRES GENERACIONES DE MUJERES EN ARQUEOLOGÍA DEL NOA” (2017)}

En los considerandos de la primera convocatoria nos apoyamos en el pensamiento de que el devenir académico de la arqueología en Argentina tenía ya una importante trayectoria que no ha sido ajena a los vaivenes políticos que se han desarrollado en nuestro país. Y en ese sentido, la equidad de género y la necesidad de las mujeres de pensarse en sus condiciones y contextos de trabajo es un reclamo de nuestros tiempos. A partir del aporte de Bellelli et al. (1993), sabíamos que son escasas las arqueólogas argentinas que en los últimos 50 años del siglo $\mathrm{XX}$ han llegado a ocupar altos cargos en organismos de ciencia y tecnología y han formado varias generaciones de discípulas/os. Pero, aun así, nos interesaba conocer cómo eran las condiciones de producción en sus inicios y cómo fue la transmisión de conocimientos de mujeres a mujeres, requisito para poder construir no solo historiografías y genealogías, sino para comprender nuestras propias construcciones como científicas y universitarias.

El primer encuentro fue posible porque contábamos con la generosidad de Patricia Arenas, colega antropóloga social del Instituto de Arqueología y Museo de la Universidad Nacional de Tucumán, que, interesada en los temas de género desde 
las perspectivas trans y de salud reproductiva, nos ofreció gratuitamente para el encuentro las locaciones de lo que entonces eran su hostal y su casa en La Ovejería, en el valle de Tafí (Tucumán); pero también puso su cabeza crítica para ayudarnos a pensarlo. La docena de camas disponibles le imprimió al encuentro un límite de personas que podríamos asistir, por lo que optamos por un formato intimista e introspectivo como metodología común en los ámbitos feministas, como el testimonio en círculo de la palabra, donde cada persona cuenta lo que quiere y como quiere a partir de una pregunta común y el resto escucha atentamente, pero puede interrumpir solo si es necesaria alguna aclaración. Así, la palabra circula en un clima de mucha introspección y sensibilidad colectiva, abriendo puertas que a veces han sido tapiadas en nuestras propias vidas. Patricia Arenas y Bárbara Manasse se sumaron a la organización, en su carácter de vecinas de Tafi, y al comité académico, en su carácter de colegas.

Nos propusimos invitar al primer encuentro a aquellas que se inspiraron o se identificaron en alguna parte de sus respectivas trayectorias con la arqueología del Noroeste argentino y con una (o más) mujer arqueóloga argentina como formadora (ese ejemplo único que una elige cuando dice "a mí me formó tal persona": podía ser una directora de beca, tesis, de carrera, de equipo, profesora, etc., pero básicamente coincidir con que formáramos o hubiéramos formado parte de su equipo de investigación). Asumiendo la formación académica como un proceso complejo, sinuoso en sus límites, que va tomando derroteros varios, se tornaba algo imprecisa la categoría de "quien nos formó", por lo que invitamos a tres generaciones de arqueólogas del Noroeste argentino que consideramos que se encontraban "genealógicamente" conectadas, en el sentido de que habían sido formadoras y formadas entre sí. La primera generación era la más fácil, porque fueron y son pocas. No obstante, algunas no pudieron asistir. La dificultad fue al convocar a las de la tercera generación, porque solo pudimos invitar a una "discípula" de cada arqueóloga de la segunda (en general a la mayor de ellas), ya que no era posible invitar a todas (Figura 1).

La composición grupal quedó finalmente así:

- Primera Generación de Formadoras: dos arqueólogas investigadoras/docentes, formadas en las universidades nacionales de Rosario y Buenos Aires y docentes en la Universidad de Buenos Aires.

- Segunda Generación de Formadas y Formadoras: seis arqueólogas investigadoras/docentes, formadas en las universidades nacionales 
de La Plata y Tucumán, y docentes en Jujuy, La Plata, Buenos Aires y Tucumán.

- Tercera Generación de Formadas y Formadoras: cinco arqueólogas investigadoras/docentes, formadas en las universidades nacionales de La Plata, Tucumán y Buenos Aires, y docentes en La Plata, Buenos Aires y Tucumán.

- Veedora Antropóloga-Etnógrafa: una antropóloga social formada en la Universidad de Buenos Aires y docente en Tucumán y Santiago del Estero.
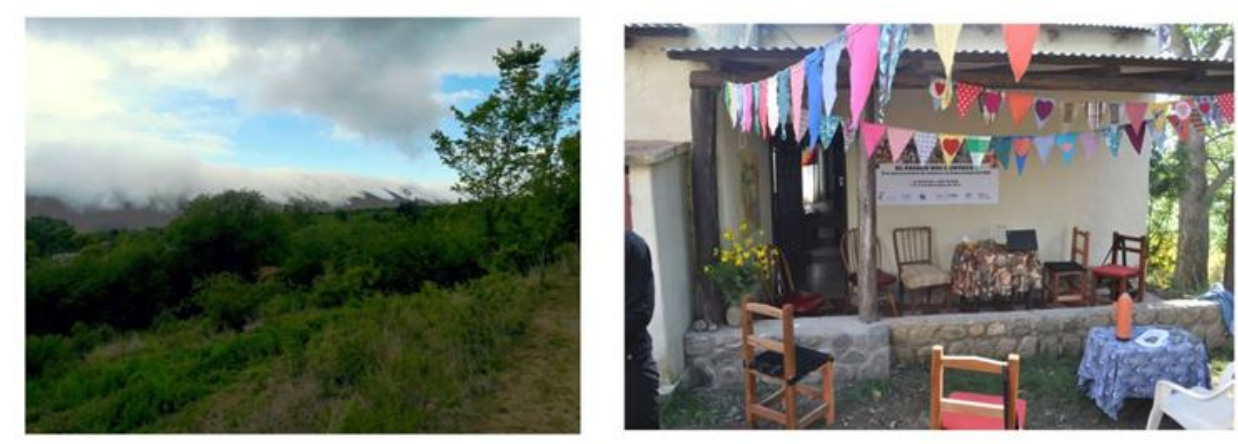

Figura 1. Izquierda: La vista que teníamos del valle de Tafí. Derecha: La decoración alegre para el encuentro. Figura en color en la versión digital.

\section{Lo planeado}

La invitación y luego las dos circulares, ya tenían un guiño de camaradería que fue parte de lo que nos permitió compartir con alegría y entusiasmo casi estudiantil el encuentro. Excepto para las invitadas de la primera generación, ya jubiladas, cuyos gastos de pasajes fueron una invitación del encuentro ${ }^{4}$, el resto fue realizado con los aportes personales de cada una de nosotras, que lo tomamos un poco como un encuentro de celebración de nuestros recorridos profesionales.

Párrafos como estos de las invitaciones y circulares dan cuenta del carácter diferente del clima de trabajo, que aun así creó un evento científico:

"Encuentro cordial y pequeño, entrevistas, fotos, recuerdos de campo y laboratorio, condiciones de producción, sistema científico y universitario, anécdotas, algún secreto...”. 
"Este encuentro es de mujeres. Nos dimos cuenta, en muchas charlas de campo, que nosotras éramos mujeres arqueólogas formadas por mujeres arqueólogas".

"Ellas/nosotras, somos las convidadas a este encuentro amable y memorioso...".

"Lugar: Tafí del Valle, Alojamiento Las Dalias + Casa de Patricia Arenas, nuestra generosa anfitriona. Solo habrá que pagar gastos de limpieza, gas, etc. 'a la canasta"” (Figura 2).

"Estamos en etapa de solicitud de avales (quizás en algunos les pedimos las direcciones de sus lugares de trabajo para pedirlos). Si se les ocurre dónde pedir algo de dinero para movernos y estar, se agradece...”.

"Fecha: del 7 al 10 de diciembre, incluyendo viaje de llegada y día de regreso. Como cada una pueda".

"Viendo que los horarios son afines, las buscaremos en la terminal y partimos desde ahí para Tafí. Almorzaremos en el Parque Temático Histórico del Bicentenario Ciudad de Famaillá y que se hagan agua todos los picolés (esto está dicho en tucumano básico)".

"COMIDAS" (nos divirtió armar nuestro menú, mezcla de menú de campaña y de picnics soleados). "Desayunos y meriendas: pan/café/té/mate cocido/ dulce/manteca. Viandas de almuerzo: canelones de berro, ricota y nuez; cazuela de llama con papas al malbec; empanadas, asado, postre regional. Cenas, cocinamos nosotras: guiso de lentejas; espaguetis al gusto; papas campesinas (receta magistral de Ale en campaña). Habrá agua, vino y un Gancia. Si alguna toma gaseosa u otra cosa, avisar".

"ACTIVIDADES: Fogón y chayada a la Pacha. Ronda para discutir los objetivos de la reunión y acuerdos entre las participantes. Generación de consensos sobre confidencialidad y producto final posible. Reunión de trabajo con Primera Generación como protagonistas. Se pide a todas las participantes que piensen las preguntas que les quieran hacer a ambas. Continuación actividades de la mañana: cómo surgen estas genealogías y entrevistas formales grabadas a Myriam y Marta. Merienda con fotos. Reunión con incorporación de Segunda Generación. Se pide a todas las participantes que piensen las preguntas que les quieran hacer. Tarde: se incorpora la tercera generación. Discusión general y comentarios de Patricia 
Arenas. Almuerzo en el Castillo de Piedra. Vienen algunas de la cuarta generación. Visita a un sitio arqueológico (permiso mediante) con la guía de Bárbara. Nochecita libre, si hubiera alguna peli para compartir, sería lindo".

"POSIBLES TEMAS PARA CONVERSAR (y realizar alguna entrevista) según preguntas que nos andan rondando (no es cerrado a esto, ni siquiera tiene que ser necesariamente así):

¿Cómo surge la vocación siendo la arqueología una profesión poco conocida y en algunos casos la carrera no existía?

¿Cómo fue la receptividad familiar al elegir la carrera?

¿Quiénes fueron los/las maestros/as formadores/as?

¿Cómo eran las campañas en las décadas de 1960, 1970 y subsiguientes?

¿Cómo era la convivencia en el campo entre géneros? ¿Era el ambiente arqueológico un ambiente asexuado o eran grupos erotizados, con el tema de conocerse tan de cerca en el campo?

¿Cómo era la relación con los colegas de otros países? ¿Cuál era el rol de las mujeres en aquellos países?

De aquel pasado ¿qué te hubiera gustado que perviva y, por el contrario, qué cambios de la actualidad te hubiera gustado que existieran antes?

¿Cómo eran las campañas arqueológicas de entonces? ¿Cuánto duraban? ¿Cómo compatibilizaban estas con la vida familiar? ¿Había alguna particularidad entre ser mujer y estar en campaña?

¿Cuál es tu perspectiva sobre el papel de las mujeres en la ciencia y su igualdad de oportunidades ante los varones? ¿Cómo lo viviste vos? ¿Sentiste libertad de acción en tu carrera o en algunas cosas podía ser que tus oportunidades y posibilidades fueran mayores o menores?

¿Considerás que en la actualidad se acentúan o desdibujan las diferencias en cómo hace arqueología una mujer? pensando desde el lugar que hay más igualdad, pero también más conciencia femenina e incluso líneas explícitas de arqueologías feministas. 
¿Qué anécdota podés compartir con nosotras que haya sido remarcable por lo risible, trágica o trascendental de lo que viviste en aquellas épocas?

¿Alguna de ustedes estuvo activa en sus carreras durante los años de la dictadura (1976-1983) y le tocó vivirlo o bien por el exilio o bien por haberse quedado en país? ¿Qué lugar te tocó vivir y cómo lo viviste? ¿Cómo fue la arqueología de aquella época? ¿Cómo atravesó la dictadura la posibilidad de hacer arqueología?"

“¿QUÉ TRAER? Para trabajar: Fotos antiguas y actuales, cartas, libretas de campo, documentos, posters viejos, películas o audiovisuales. Lo que quieran compartir... (habrá dos scanner, 2 notebooks, un cañón, una pantalla, una cámara de fotos buena, muchos celulares). Posibles temas para conversar, según preguntas que nos anden rondando. Preguntas para las dos primeras generaciones. Si quieren traer algún último libro o publicación para vender/compartir. Para vivir: Abrigo, campera de lluvias, paraguas, linterna. Zapatilla para cargar celulares todas a la vez (tres patitas en V son las tomas de la casa). Off."

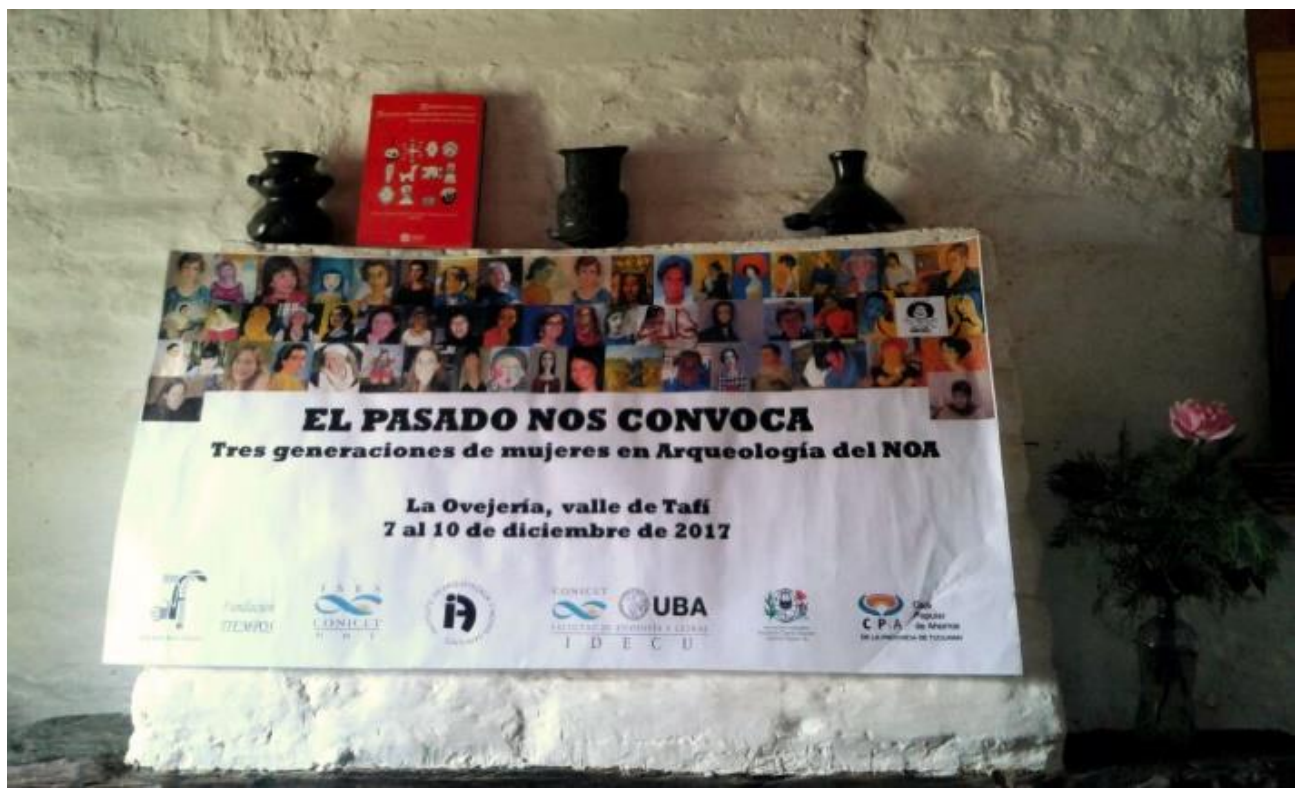

Figura 2. El banner que nos acompañó desde la chimenea de la casa Arenas-Méndez. Figura en color en la versión digital. 


\section{LO NO DICHO, LO REALIZADO Y LO OBTENIDO}

\section{Lo no dicho}

Empecemos por decir que tuvimos críticas al momento de organizar este encuentro. Ninguna frontal, que pudiéramos conversar, responder y explicar, pero igual nos llegaban, como llega todo cuando alguien está disconforme...

Entre las mujeres no invitadas hubo ofensas ¿Por qué solo "ellas"? ¿Por qué piden subsidios y auspicios para esto? ¿Por qué no se juntan entre ellas a tomar el té y ya?

Entre algunos varones la sensación de desplazamiento de un encuentro que también hubieran querido compartir. Con ese formato especialmente.

Y desde los varones y mujeres en posiciones de poder, si bien tuvimos un apoyo fundamental en el Consejo Nacional de Investigaciones Científicas y Técnicas (CONICET) propiciado por Dora Barrancos, con una declaratoria de interés por el evento y, a partir de ello, varios auspicios, sabemos que también hubo críticas por el formato cerrado del encuentro. Debemos decir que en el ámbito científico hay muchos encuentros cerrados, prácticamente todos aquellos con formato taller. Pero este era solo de mujeres; la categoría de ser mujeres arqueólogas del Noroeste formadoras de mujeres no parecía suficiente ¿Qué nos traeríamos entre manos?.

Recién al escribir este artículo nosotras dos nos permitimos reflexionar sobre esto que, en su momento, solo nos hizo llevar la cabeza de un lado a otro con incredulidad y tristeza. ¿Por qué la reunión de mujeres es siempre sospechosa? ¿Y por qué si se le suma el placer de hacerlo disfrutándolo de un modo amable y cuidado es más sospechoso aún y deja de ser "científico"? ¿Por qué se nos acusa de ser "todas amigas y que se junten a tomar el té" si nos hemos conocido trabajando y compartiendo una trayectoria en común, sobre la que queremos reflexionar para producir conocimiento? ¿Por qué un evento donde todos se gritan, se exaltan, se paran y ejercen sus diferentes juegos de poder es considerado, en cambio sí, un evento científico exitoso? ¿Acaso las prácticas profesionales son valoradas solo cuando son rugosas, cuando producen machucones, algún grito, alguna pregunta impertinente y exaltada? ¿Quién establece las reglas de una reunión y el clima que tiene que tener para ser considerado científico? ¿Qué es lo que tanta zozobra generaba? ¿Acaso el miedo de que hablemos y demos a conocer temas tabúes en arqueología? ¿Denuncias de violencia de género? ¿Alguien temió un aquelarre punitivista? 


\section{Lo realizado}

Pasado ese mal trago de las críticas de pasillo que no se explicitaban delante nuestro, tomamos nota de aquello que sí considerábamos válido de lo dicho sin expresar: había más gente que quería compartir algún momento, sobre todo con las invitadas que venían de lejos. Es por eso que el cuarto día lo planificamos como un día abierto, con invitaciones a todos y todas los, las y les que quisieran asistir, incluso a colegas varones. La invitación a este día arqueológico y de asado de camaradería era abierta y enviamos esta invitación amorosamente, con una escritura cuidada y buscando una respuesta receptiva. Solo nos respondieron algunos varones, agradeciendo y diciendo respetuosamente que preferían no cortar el clima de una reunión que, entendían, era nuestra y nos merecíamos tener. Y luego las jóvenes becarias, doctorandas y estudiantes de la carrera de arqueología de la UNT que tienen vínculo laboral con algunas de nosotras, se tomaron un colectivo de línea y vinieron al asado y a conocer uno de los sitios arqueológicos del valle con la guía experta de Bárbara Manasse. Fue una excepcional ocasión para compartir un día de reflexión conjunta, camaradería y visitar en grupo un sitio arqueológico en el valle de Tafí, pero también para seguir formando lazos intergeneracionales. No siempre las más jóvenes conocen a aquellas que leen solo en la bibliografía. Y no siempre las mayores sabemos cuáles son las inquietudes y problemas de las más jóvenes. Nos parecía importante darles/darnos corporalidad y presencia en este mismo espacio de cuidado y sororidad. Y de algún modo, ese día nos inspiró para organizar el segundo encuentro... (Figura 3).

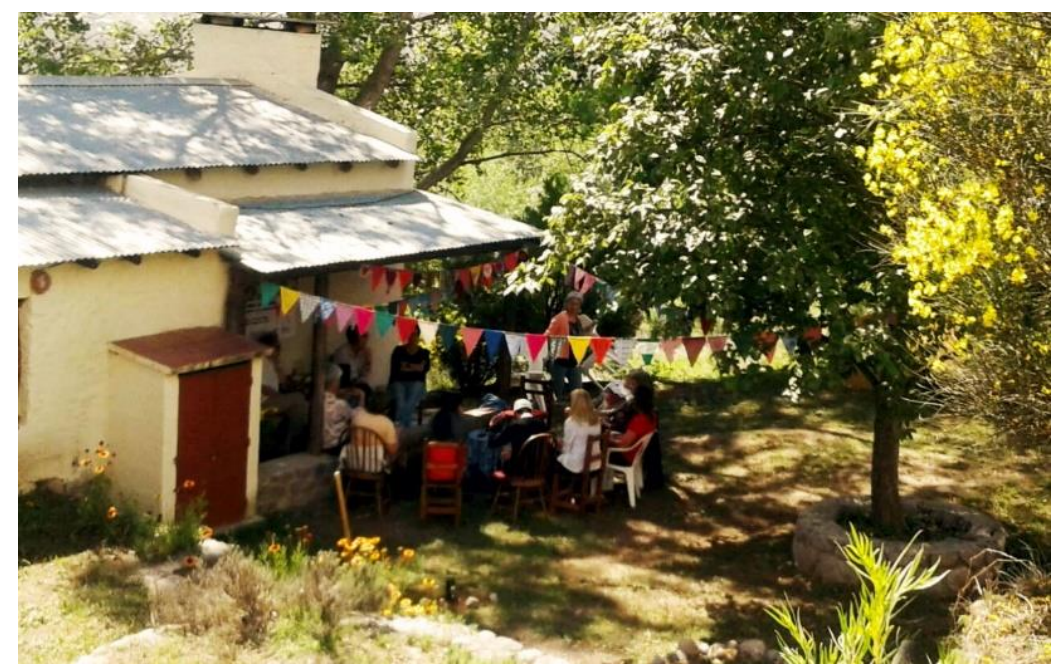

Figura 3. Las integrantes del primer encuentro en círculo de palabra. Figura en color en la versión digital. 


\section{Lo obtenido}

El encuentro completo fue maravilloso y lo recordamos todas hasta el día de hoy como un hecho memorable. Y es que, por primera vez en nuestras carreras tuvimos un espacio cuidado donde compartir los sabores y sinsabores de nuestra profesión con mujeres referentes, cuyos trabajos seguíamos o de los cuales también éramos parte.

Las rondas de testimonios, por supuesto, fueron lo central de esos días. La escucha fue atenta, pero, a la vez, las grabaciones muestran el clima de interés y de interconexión de historias que cada una que tomaba la palabra generaba. Tuvimos que poner para cada oradora una (1) hora como tiempo límite de exposición que, si bien resultó finalmente laxo, nos ayudó a ordenarnos. Compartir relatos y experiencias nos llevó a reflexionar desde una perspectiva de género y ahí vimos cómo cada generación de arqueólogas se posicionaba diferente y cómo esas posiciones nos llevaban a nuevas reflexiones y debates.

Las dos representantes de la primera generación que estuvieron presentes tuvieron un espacio más amplio para proyectar un recorrido de sus vidas con diapositivas, a modo de conferencias informales. También se hizo el registro audiovisual de las entrevistas a ellas, Marta Ottonello y Myriam Tarragó, que dado su formato para todo público podrían ser editadas y compartidas, pero siempre en ese mismo clima de revisar lo dicho, de no mostrar sin acuerdos previos. En eso también, este cuidado feminista y el respeto a los acuerdos sobre qué se muestra y qué no y cuándo, tiene intersecciones con las arqueologías indígenas o subalternas a las que hacía referencia Conkey (2005).

Otras actividades, muy importantes y cohesionadoras, fueron las tertulias nocturnas, donde se compartieron fotos, videos, cartas y relatos escritos (Figura 4). En esas tertulias cada imagen que aparecía se intercalaba con anécdotas y el interminable acertijo de hacer coincidir caras con nombres de las diversas fotos que veíamos. Todo esto en una atmósfera de alegría, asombro, risas y también llanto. (Figura 5) 

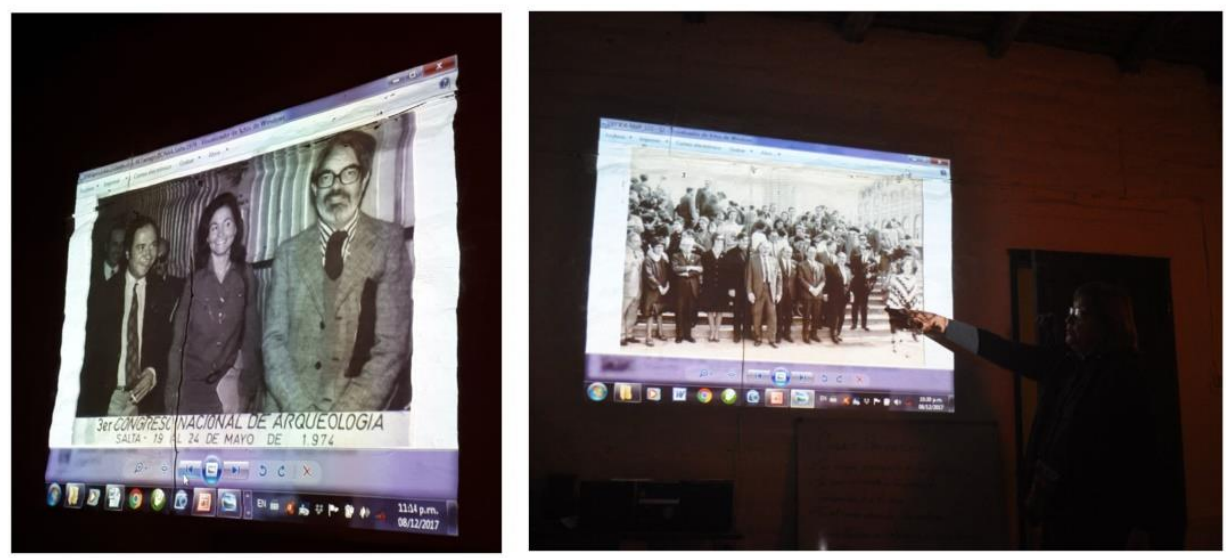

Figura 4. Historia de la arqueología desde la presentación de Myriam Tarragó. Figura en color en la versión digital.
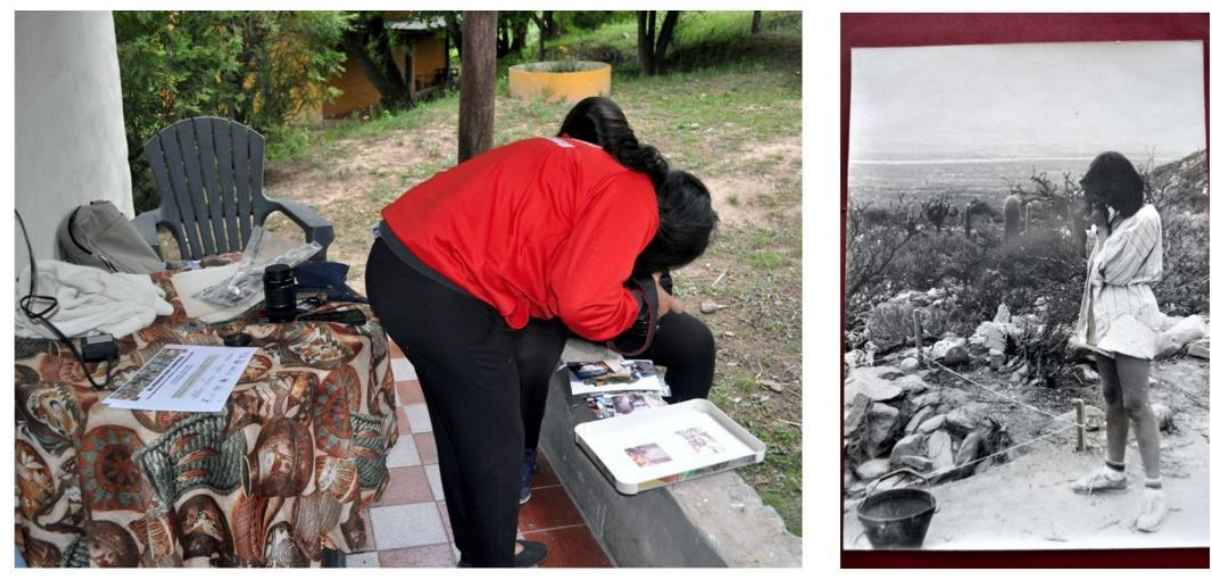

Figura 5. Izquierda: La documentalista Ana María Atienza, registrando las fotos y documentos que llevaron las invitadas para ser ordenados. Derecha: Una foto de archivo aportada por Cristina Scattolin. Figura en color en la versión digital.

$\mathrm{Y}$ por supuesto que la experiencia de estar en un espacio reflexivo y tranquilo, todas juntas comiendo y durmiendo en un lugar lejos del pueblo y con poco acceso a internet, le dio un plus de tiempo de conversaciones, risas, puestas al día en noticias familiares, chismes, bromas, expectativas, etc., que se parece solo a la experiencia de campaña arqueológica misma.

Finalmente, el asado de camaradería del último día con la cuarta generación, al sol, en el pasto, compartiendo experiencias, fue muy importante para 
entender cómo había ido variando la práctica de la profesión con los años; cuánto le debíamos a las generaciones precursoras, abridoras de caminos, y cuánto estábamos aprendiendo de las miradas más jóvenes sobre temas que las mayores teníamos naturalizados. (Figura 6)

Nos llevamos algunas reflexiones y tareas "para la casa", y la invitación de Mariette Albeck a que el próximo encuentro fuera en su casa de Uquía.

Hasta entonces, no teníamos un rumbo claro de cómo queríamos seguir. Dos años después, cerca de Uquía, en Tilcara, y con la participación de mujeres muy jóvenes, se fueron despejando las incógnitas y juntas le dimos una dirección más definida a nuestros objetivos.

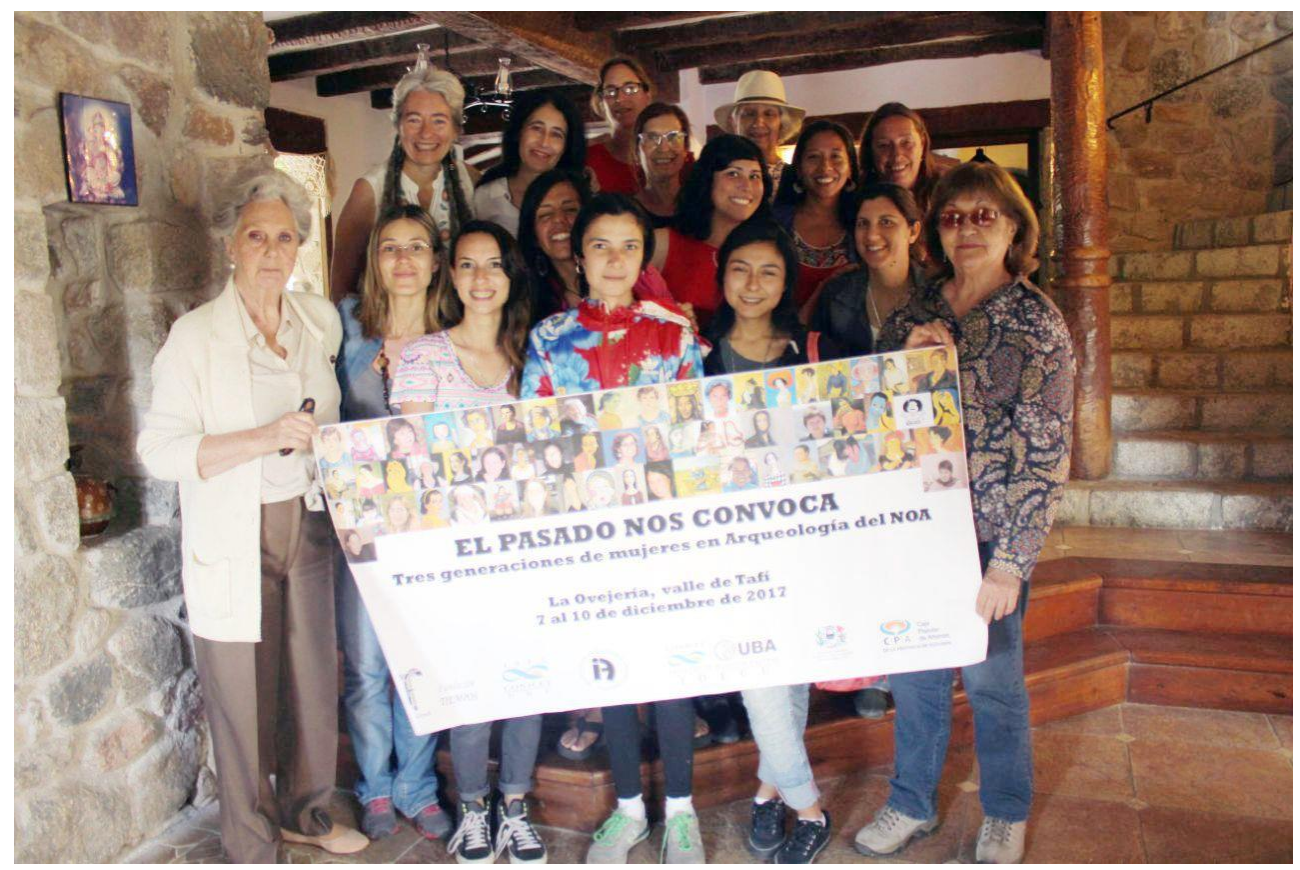

Figura 6. Foto grupal con la generación más joven (varias de las otras participantes ya no estaban en Tafí al tomarla). Figura en color en la versión digital.

\section{SEGUNDO ENCUENTRO, "EL PASADO NOS CONVOCA (II): ARQUEOLOGÍA DEL NOA GENERADA POR MUJERES” (2019)}

A partir de los resultados positivos y entusiastas de la reunión en el valle de Tafí decidimos la organización de una nueva reunión en Tilcara, Jujuy, los días 29 y 30 de noviembre de 2019, totalmente abierta a todas las arqueólogas de la región NOA (hayan sido formadas por mujeres o no). La realización de este segundo 
encuentro/taller sobre las experiencias personales y académicas de arqueólogas de distintas generaciones tuvo como objetivo contribuir con nuevos aportes a la historia de la arqueología en Argentina, a través de los propios derroteros personales y académicos, atravesados por distintas coyunturas políticas. En la convocatoria de esta nueva reunión se solicitaba a las interesadas enviarnos una carta de intención para participar en los talleres definidos previamente. La respuesta fue enriquecedora y contundente, y mostró el gran interés en ser partícipes y protagonistas de este nuevo encuentro. Debemos decir que, ahora que la reunión era abierta a "todas las arqueólogas que trabajaran en el NOA", la crítica de pasillo (pero esta vez explícita y a modo de protesta risueña) fue de aquellas profesionales de la biología, ciencias del suelo, geólogas, etc., que trabajan interdisciplinariamente con nosotras o en otros grupos. Sabíamos que también tenían razón y de hecho una se nos coló (y su testimonio fue maravilloso); pero en algún punto, otra vez sin dinero ni recursos, no podíamos hacer un gran congreso. Para realizar este nuevo encuentro solicitamos ayuda económica para reuniones científicas al CONICET, un subsidio modesto que fue otorgado y agradecemos. También contamos con la colaboración del Instituto Interdisciplinario de Tilcara, dependiente de la Facultad de Filosofía y Letras de la Universidad de Buenos Aires (UBA), que puso las aulas para el encuentro y la Residencia Universitaria. Clarisa Otero se sumó a la organización y al comité académico, oficiando de imprescindible ayuda local en todas las ocasiones, días y situaciones a resolver. (Figura 7)

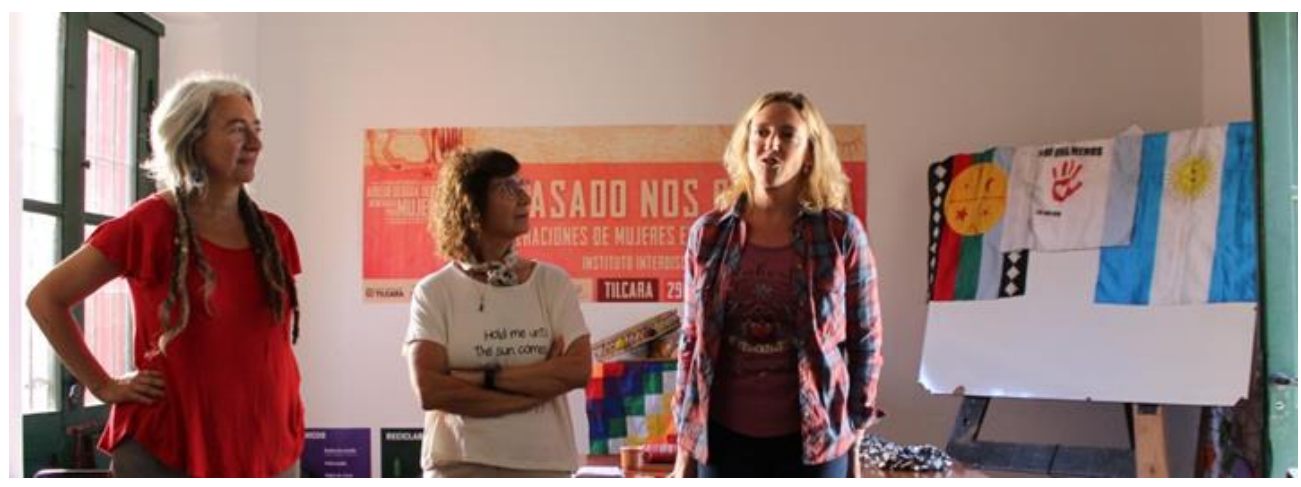

Figura 7. Recibimiento y presentación del Encuentro en el Instituto Interdisciplinario Tilcara. Figura en color en la versión digital. 


\section{LO PLANEADO, LO REALIZADO Y LO OBTENIDO}

\section{Lo planeado}

El Segundo Encuentro tenía como objetivos:

1. abrir las invitaciones a otras colegas y tener una mirada externa desde el campo de estudios de género desde las experiencias vividas;

2. trabajar en material recuperado en el Primer Encuentro/taller, pensando un formato de "Archivo Digital de la Memoria arqueológica"; y

3. escribir un libro "colectivo"

Este encuentro nos permitió ampliar nuestro horizonte con un recorrido desde una perspectiva hasta ese momento nunca abordada - esto es, la mirada de género- de las prácticas arqueológicas del NOA en el campo, en el laboratorio y en los claustros universitarios entre los años sesenta y la actualidad.

\section{Lo realizado}

Con la inclusión de nuevas generaciones, la mañana del primer día se realizaron las presentaciones correspondientes y se invitó a completar una encuesta para confeccionar un cuadro con datos como nombre, edad, grado alcanzado, posgrado, referentes, pares $\mathrm{y}$, de especial importancia para poder ubicarnos, cuál había sido el episodio histórico argentino que había marcado su vida. Esta primera cronología nos permitió distinguir cinco grupos: uno más impactado por la primera dictadura, que corresponde al año 1966 con el derrocamiento de Arturo Humberto Illia y la toma del poder por parte de Juan Carlos Ongania; el segundo grupo impactado por la dictadura de 1976-1983; el tercer grupo con dos antecedentes claros como el gobierno de Carlos Menem y la crisis del 2001; el cuarto grupo con las presidencias de Cristina Fernández de Kirchner y Mauricio Macri; y el quinto grupo marcado por el feminismo, temática que se superpone con varios momentos pero que puede ser elegida como central. (Figura 8)

Posteriormente, se desarrollaron siete exposiciones de las primeras generaciones y, como cierre del primer día, Myriam Tarragó ofreció una emocionante conferencia a la que tituló "Deconstruyendo el sendero. De cómo me hice mujer/arqueóloga", durante la cual desarrolló cuatro aspectos: 1. Familia; 2. Contexto sociopolítico y educación; 3. Docencia/Investigación; y 4. La Academia: participación e intercambio. (Figura 9) 


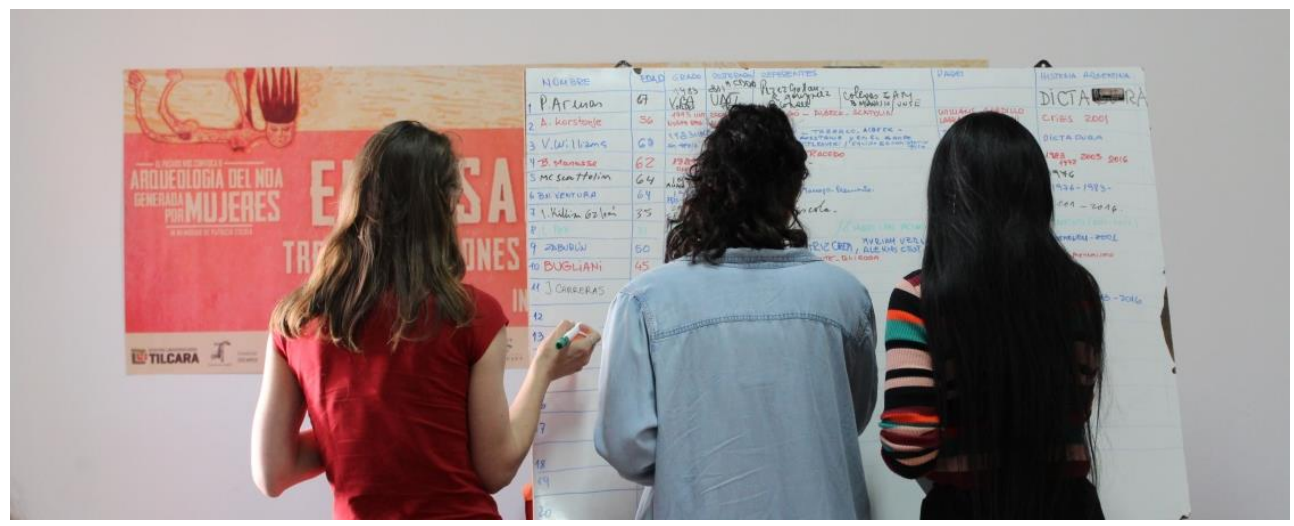

Figura 8. Cada participante completa el cuadro sus datos para crear una "cronología de generaciones". Figura en color en la versión digital.
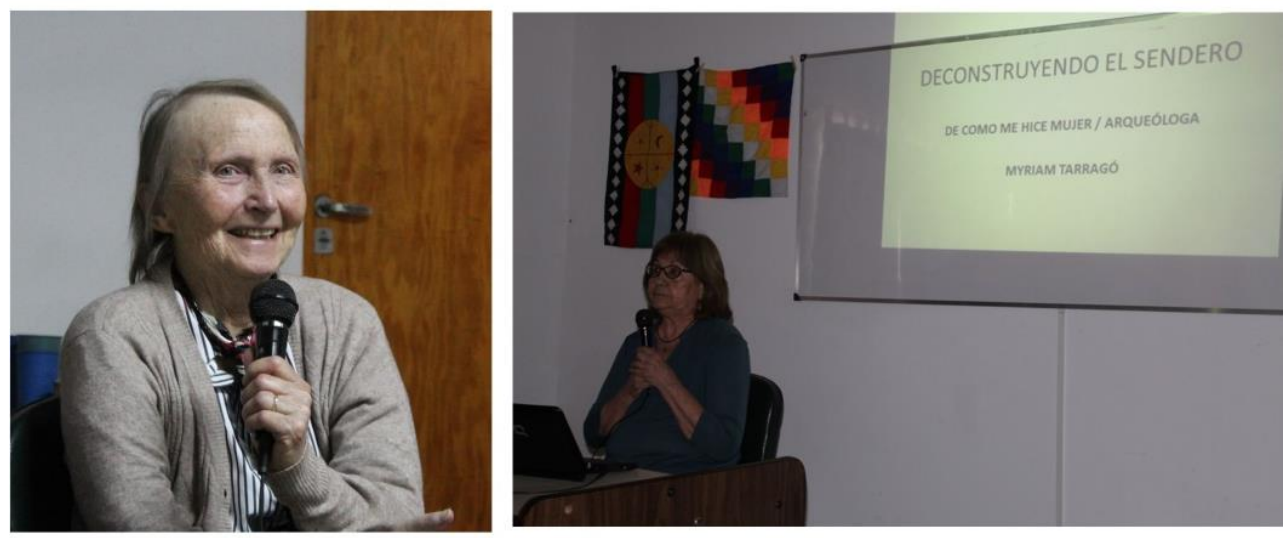

Figura 9. Izquierda: Mariette Albeck relatando su trayectoria. Derecha: Myriam Tarragó dictando su conferencia. Figura en color en la versión digital.

Al día siguiente continuaron las tandas de expositoras: las arqueólogas de la segunda, tercera y cuarta generación. Y otra vez volvió la magia de la empatía y sororidad con nuestras colegas al escuchar sus historias de vida como personas y como profesionales, y quedó muy marcado el cambio que vimos en las presentaciones más jóvenes, con la claridad de saber y reconocer situaciones de micromachismos, de violencia laboral, no solo por parte de varones, sino también de mujeres, de desigualdad en situación de poder, mucho más que las representantes de la primera y segunda generación, que hemos naturalizado tales desigualdades y prácticas. (Figuras 10 y 11)

Tal como había sucedido en La Ovejería en 2017, en Tilcara las rondas de testimonios fueron lo central del encuentro y tuvimos que tomar la decisión de 
cambiar el cronograma sobre la marcha. Los dos días de reunión estuvieron colmados por los sentidos y profundos testimonios de las cuatro generaciones, y eso que esta vez habíamos reducido el tiempo de exposiciones a media hora por persona. Por ende, los talleres propuestos quedaron como una actividad pendiente para el futuro. La escucha de cada testimonio tuvo la misma intensidad que aquellas de la primera reunión, así como el interés y la interconexión de historias entre las participantes.

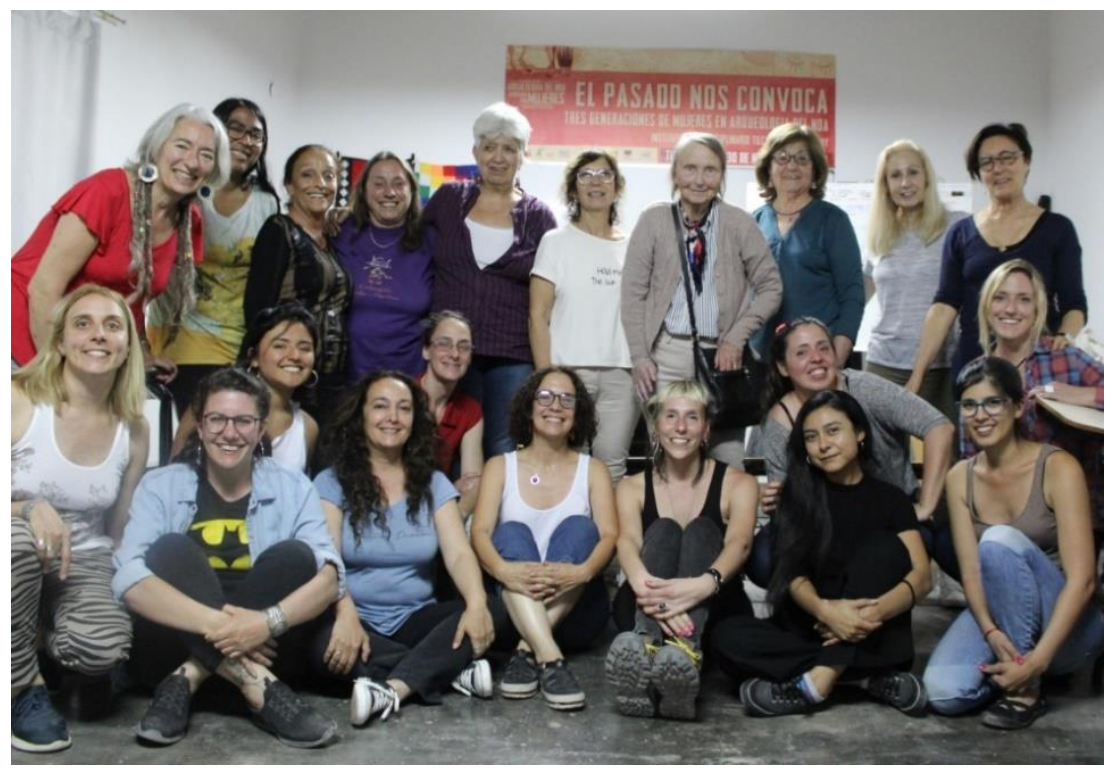

Figura 10. Algunas de nosotras en la primera jornada de trabajo. Figura en color en la versión digital.

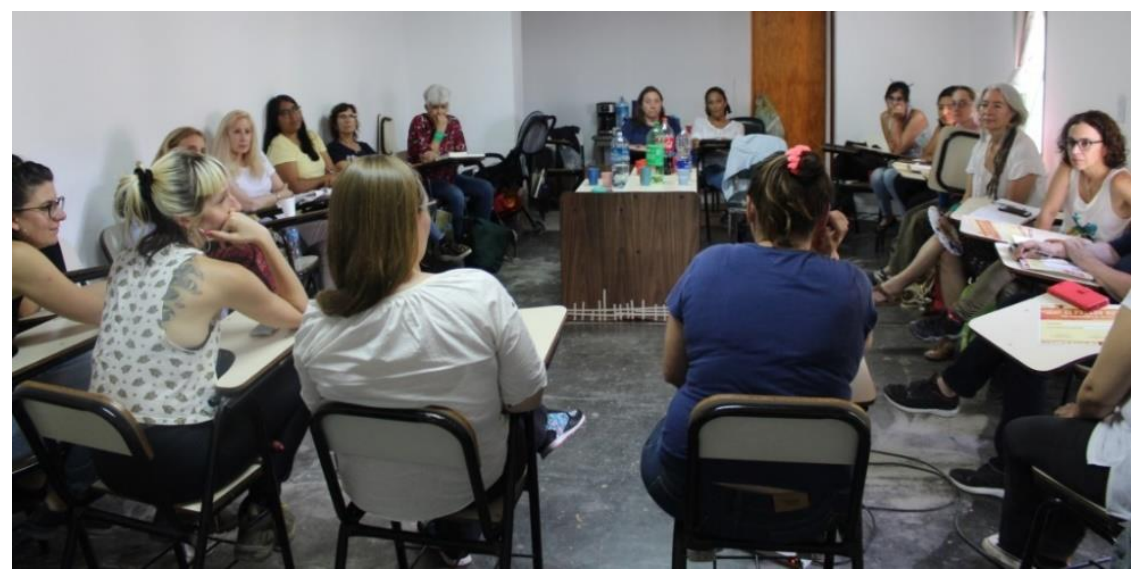

Figura 11. Desarrollo del segundo día del Encuentro en Tilcara. Figura en color en la versión digital. 
De todos modos, estos fueron los temas que se propusieron y ordenaron antes del encuentro y estuvieron presentes en nuestras exposiciones, de uno $\mathrm{u}$ otro modo, a saber:

1. ARQUEÓlOGAS JÓVENES ¿OTRO MUNDO ES POSIBLE? (las arqueólogas y su participación en la construcción de una nueva subjetividad femenina). Aquí el interés recolectado comprendía desde investigar prácticas sociales cotidianas del trabajo en territorio y en el contexto general que conducen a pensar y repensar desde una perspectiva de género o feminista para contribuir al desarrollo personal y profesional, pasando por el descubrimiento de la Arqueología Feminista como motivación política, que implica "transformar las relaciones sociales actuales" cuestionando la desigualdad de género en los distintos ámbitos que transitamos, hasta socializar experiencias en el campo sobre una etnografía de mujeres puneñas y compartir saberes más allá de las "recetas" o discursos preestablecidos propios de los espacios que propone la Academia.

2. ARQUEÓLOGAS GESTORAS/DIRECTORAS (compromiso en medios rurales e indígenas, conformación de equipos y lugares de toma de decisiones al interior de los equipos).

\section{ARQUEÓlOGAS Y ROLES MÚLTIPLES: MADRES, ESPOSAS,} TÍAS, ABUELAS (Reflejos de conductas machistas propias, en el medio, micromachismos, etc.). Aquí el mayor interés fue el de compartir vivencias en roles múltiples en sus propias historias de vida, así como las de otras mujeres con las que atravesaron distintos momentos históricos hasta la actualidad, signados por el impacto y devenir del modelo patriarcal. O el de compartir experiencias de trabajo en regiones consideradas tradicionalmente como "adversas" para la investigación arqueológica. $\mathrm{Y}$ en este contexto, discutir y comparar con otras colegas aquellas prácticas donde, como mujeres, se toman decisiones que impactan tanto en los avances de la disciplina, como en la formación de nuevo/as investigadores/as. Y se hizo constante referencia al momento político del país durante la formación académica como la deconstrucción de una mirada dominada por la fuerte impronta patriarcal y machista, instaurada durante la dictadura militar.

4. ARQUEÓLOGAS Y COMPROMISO INSTITUCIONAL E INTERNACIONAL (los compromisos con? de? las propias instituciones de pertenencia).

También, como sucedió en Tafí, existieron momentos de reflexión y haceres conjuntos como mateadas, fogones, música con la cantante Soema Montenegro, preparación de comidas previa ofrenda a la Pachamama, fotos y algún video compartidos, así como charlas con otras mujeres, cuyos quehaceres son conexos con la arqueología (comuneras indígenas de la zona, no-docentes del Instituto Interdisciplinario Tilcara, artesanas, etc.). (Figura 12) 


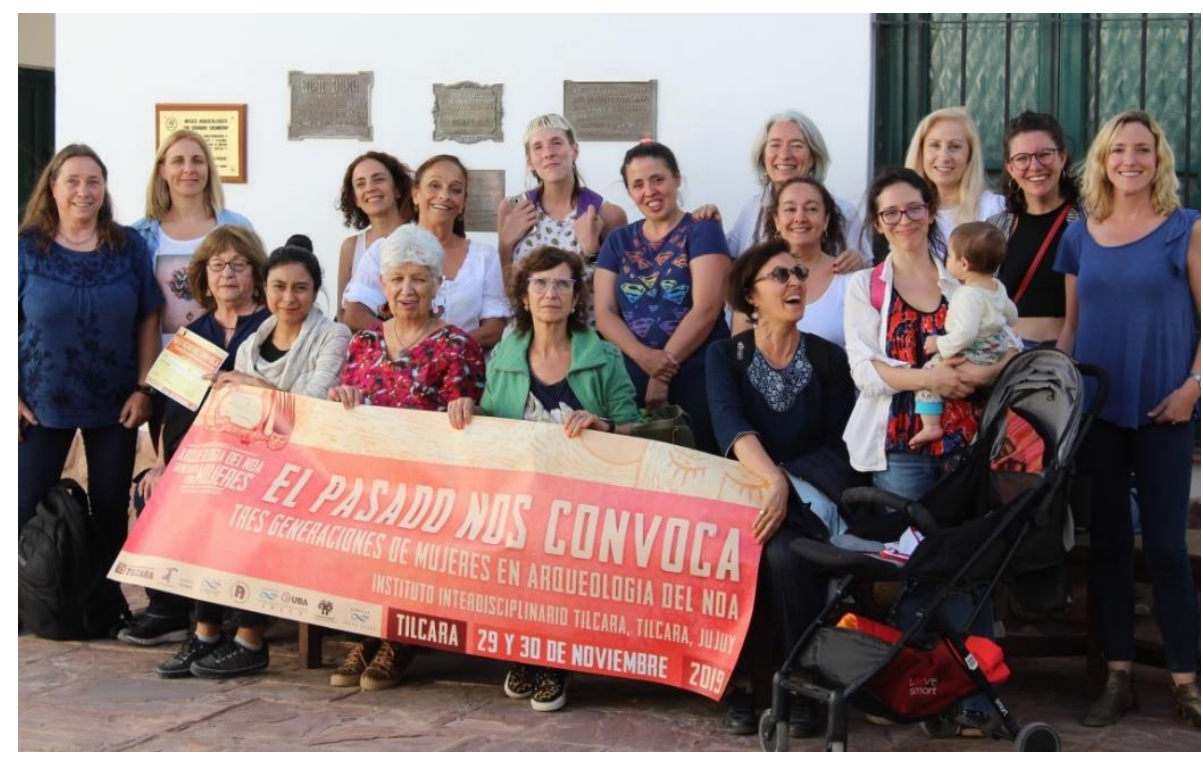

Figura 12. Final del Encuentro “El Pasado nos convoca”. ¡Misión cumplida!. Figura en color en la versión digital.

\section{Lo obtenido: el futuro del pasado nos convoca (III)}

Al igual que en el primer encuentro, nada de lo generado y conversado en los talleres sale de allí sin autorización explícita de las autoras porque los testimonios son privados y con otra información se prevé realizar una obra colectiva.

Nos parece importante señalar que seguimos organizadas, ahora de un modo más horizontal, para realizar un nuevo encuentro ${ }^{5}$ que articule con otras mujeres arqueólogas argentinas y sudamericanas que sientan que tienen algo que decir, escuchar o compartir sobre el tema.

Se han abierto nuevas temáticas en el grupo, pero mantenemos la idea de no escribir sobre esto sino es de modo grupal y consensuado. Solo podemos adelantar que parte de nuestro perfil colectivo está en la búsqueda de una historia de la arqueología argentina centrada en algunos temas que nos interesan como mujeres y disidencias. Eso incluye nuestras historias de vida, trayectorias personales, para poder así delinear el derrotero de la disciplina en los últimos 60 años, participando como testigos de primera mano de diferentes momentos del país, con diversos gobiernos, cuyas administraciones han incidido en el desarrollo científico tecnológico de Argentina; periodos en los cuales se han producido giros ontológicos, nuevos abordajes metodológicos y cambios en la práctica profesional. Trataremos de registrar una historia como un relato cronológico, analítico y 
valorativo, resultado de la suma de una serie de relatos vividos por las protagonistas y articulados en sus contextos. Esto incluirá también la organización, curaduría y digitalización de nuestros archivos audiovisuales, epistolares y documentales.

La experiencia de la escritura de un texto colectivo, es decir que todas las participantes no solo escriban sobre determinados temas, sino que colectivamente se participe en todas las instancias de producción del texto, permite poner en valor experiencias de cada una en la producción de textos académicos y su comunicación. Solo es posible llevar adelante esta experiencia contando con la posibilidad de un encuentro presencial, donde el debate cara a cara permita el avance sobre el esquema del libro, realizar acuerdos y discutir estilos, formatos y cronograma de trabajo.

En ese sentido, compartimos con María Ángeles Duran (2008), la idea de que las experiencias vividas (en la arqueología) sirven/sirvieron para construir narrativas del pasado):

Estamos acostumbrados a aceptar que el modo en que conocemos afecta el modo en que vivimos. Pero no es tan frecuente lo inverso, esto es, que el modo en que vivimos afecta el modo en que conocemos. La producción de un texto -de un libro, en este caso- es un proceso de conocimiento en el que caben distintas dosis de repetición y de innovación. Muchos libros, y algunos de ellos meritorios, no son otra cosa que recopilaciones ordenadas de otros textos, de cosas ya dichas. Incluso cabe a algunos autores la habilidad de saber escuchar lo que otros dijeron tan bajito o tan encubierto que apenas se les oyó, o de forzar diálogos entre textos ajenos sin necesidad de modificarlos, haciendo brotar de ellos ante el lector lo que sin ese contraste hubiera pasado inadvertido.

Sin embargo, hay algunos raros proyectos intelectuales que se empeñan en hacer las cosas al revés de lo común y sitúan la experiencia de lo vivido en su punto de arranque, al comienzo del proceso. En esos casos, el problema de la relación entre el sujeto cognoscente y el objeto del conocimiento se plantea con toda dureza. Puede hacerse explícito, consciente, o quedar soterrado, pero sus efectos son decisivos sobre el modo en que se llega a conocer: arrastra y tira de las categorías, de los focos de luz, de los intereses que sostienen las indagaciones (Durán, 2008: 17).

En el siglo pasado, y en este, ha habido importantísimas producciones intelectuales o académicas procedentes de la conciencia de que una sola clase social no podía hablar en representación de todas. En este fin de siglo XX y 
comienzos del XXI, nos toca a las mujeres un acceso generalizado a la conciencia colectiva, a la posibilidad de re-pensar o re-crear la cultura desde su propia experiencia histórica y presente, que ha sido y sigue siendo todavía muy diferente de la de los varones.

\section{Para ir cerrando, ipor qué hay tantos grupos de mujeres arqueólogas o profesionales relacionadas con la arqueología?}

En un reciente artículo, una de nosotras junto a una colega colombiana (Korstanje y Archila, 2020) hicimos un recorrido sintético, y por ello seguramente incompleto, acerca de dos temas:

1. la reflexión sobre el pasado, o sea cómo la arqueología ha investigado en Sudamérica sobre mujeres (sexo, género, poder); y

2. la reflexión sobre el pasado reciente y el presente, o sea cómo las mujeres arqueólogas en Sudamérica hemos trabajado en un ambiente dominado por el "macho latino".

A partir de esa pesquisa hemos detectado numerosos colectivos de mujeres organizadas, conversando, denunciando, debatiendo y proponiendo. Nos une a todas ellas la convicción de que el feminismo llegó para quedarse y para generar un mundo mejor, más horizontal, menos violento, con más derechos ya no solo para las mujeres, sino también para los grupos LGTB+ y las disidencias sexuales; un mundo donde no se invisibilice al diferente, se respete y se pueda compartir. Y en el caso de nuestra profesión, una práctica donde el poder no sea ejercido a partir de redes y lobbies, sino de espacialidades y tramas con reglas más claras, propuestas en consensos.

Sin embargo, las mujeres que nos reunimos en los encuentros "El pasado nos convoca" no lo hacemos todas explícitamente desde el feminismo. Algunas de nosotras lo somos, claramente; otras más tímidamente; otras no necesariamente se identifican o conocen a fondo sus consignas políticas. Nos convocamos y pusimos, en cambio, un especial énfasis en lo intergeneracional y en el deseo de primero escucharnos y pensar, y ahora en escribir una historia de la arqueología argentina desde nuestra perspectiva.

Otra reunión de gran impacto que congregó arqueólogas del país fue el Conversatorio realizado en el marco del XX Congreso Nacional de Arqueología Argentina (CNAA) celebrado en la ciudad de Córdoba en 2019 bajo el título de "Género en la arqueología argentina. Trayectorias, prácticas y saberes: Conversatorio 2019" coordinado por María Gabriela Chaparro, Cristina Bellelli, Vivian Scheinsohn y Mónica Berón, cuyo resumen fue publicado en Práctica 
Arqueológica, el mismo año (Chaparro et al., 2019). En esa reunión se trataron temas como las asimetrías entre géneros según tres ejes: 1) las prácticas profesionales y sus manifestaciones (micromachismo, mansplaining, acoso, techo de cristal, etc.; 2) el estudio de las relaciones de género en la explicación y la interpretación del pasado y en ámbitos de difusión científica, y 3) las trayectorias personales y el desarrollo profesional en contextos patriarcales (Chaparro et al., 2019:43). Otros temas fueron la violencia de género en los ámbitos académicos, el impacto de la militancia y el activismo feminista y los debates en torno al lenguaje inclusivo. Y se destacó que el papel de la mujer en la arqueología estuvo (y muchas veces todavía está) restringido a ser anónimas "ayudantes de campo y laboratorio" y esto se reproduce en ámbitos de evaluación, como en las comisiones evaluadoras de becas, ingreso a carrera o proyectos (Chaparro et al., 2019:45).

Este Conversatorio fue una excelente ocasión para que tres de las coordinadoras, Cristina Bellelli, Vivian Scheinsohn y Mónica Berón, presentaran “25 años después de la publicación de 'Una arqueología de distinto género' ¿habrá cambiado la situación en la academia?" con la actualización del trabajo ya pionero publicado en 1993 y al que sumaron datos más actuales de CONICET (2008 y 2018) y la Universidad de Buenos Aires (2017), como las Becas UBA (estímulo y doctorales) entre 2013 y 2018.

Un dato que se mantiene es que la base de la pirámide sigue siendo mayoritariamente femenina, especialmente becarias, aunque se achica levemente en el caso de CONICET, respecto de 1993; y las direcciones continúan siendo predominantemente de varones, al contrario de la UBA donde son mayoría las directoras. Para el caso de la investigación en el CONICET la mayoría de las mujeres se concentran en las categorías inferiores de la Carrera de Investigador Científico (CIC). En los periodos muestreados los varones dominan en la categoría Superior de la CIC, elevando el techo de cristal respecto de 1993. En el caso de la UBA, las mujeres predominan entre el personal auxiliar, igual que en 1993, pero también dominan en el escalafón de profesores/as adjuntos/as, la primera categoría del claustro de profesores, y son los varones los que dominan en el cargo de profesores titulares (Chaparro et al., 2019: 44).

Por los datos vertidos, el nuevo techo de cristal se ubicaría a nivel de la falta de promoción, tanto en la CIC, como en la carrera docente de la UBA.

Como corolario, las autoras remarcan que, si bien las mujeres abrieron caminos y construyeron espacios de formación en el ambiente académico, ese peso se diluye cuando se analizan los espacios de poder donde la proporción se invierte significativamente (Chaparro et al., 2019:45).

Existen varios otros grupos o colectivos donde el feminismo es la consigna de partida, pero en el fondo las temáticas son las mismas, lo que cambia es la 
intensidad en cada tema. Por ejemplo, grupos que están más enfocados en la denuncia de la violencia, donde también participamos o donde podemos acudir. Algunos son específicos de profesionales de la Arqueología y otros son espacios interdisciplinarios donde hay arqueólogas. Por ejemplo:

- En la Red de Información y Discusión Sobre Arqueología y Patrimonio (RIDAP) se ha conformado un espacio de charlasdebates denominado "Mujeres y Disidencias en las Arqueologías Sudamericanas" (Jofré et al. en este número).

- En el Centro Nacional Patagónico (CENPAT) se ha institucionalizado el Espacio de Atención de Violencia Laboral y de Género, el Comité Institucional de Políticas de Género, y la Comisión de Igualdad de Oportunidades y Tratos.

- La Colectiva Federal, es una red de investigadoras del CONICET en el tema y a su vez de protección y denuncia de hechos de violencia o discriminación.

- En las provincias también hay agrupaciones donde hay arqueólogas trabajando, como "Las Candelarias", grupo de estudiantes de arqueología de la Universidad Nacional de Tucumán; o "Las Cornelias", que fue organizado por historiadoras, pero se han incorporado arqueólogas, y realizan distintos tipos de actividades y eventos relacionados con la visibilización de la mujer en ciencia y sus derechos.

A su vez, recientemente, en las mismas instituciones científicas se han formalizado espacios de protección, promoción, debates y empoderamiento de la mujer, a saber:

- Comisión Interdisciplinaria del Observatorio de Violencia Laboral y de Género del CONICET (2017).

- Programa Nacional para la Igualdad de Géneros del Ministerio de Ciencia y Técnica (MINCyT) (2020).

- Área de Género y Política de Género de la Agencia Nacional de Promoción de la Investigación, el Desarrollo Tecnológico y la Innovación (I+D+i) (2020).

- $\quad$ Red de Género y Diversidades (CONICET) (2021). 
- Claramente, la reciente creación del Ministerio de las Mujeres, Género y Diversidad (2019) en la República Argentina es una manifestación del vigor de nuestras luchas y propuestas.

\section{CONCLUSIONES Y PALABRAS FINALES}

Tal como sucede en la mayoría de las áreas del conocimiento científico, la antropología y la arqueología en Argentina fueron dominadas por los hombres desde sus comienzos, situación compartida por otros países de habla hispana. No obstante, algunas mujeres abrieron brecha, llevaron a cabo investigaciones y formaron nuevas generaciones de arqueólogas y arqueólogos desde la década de 1960, cuya memoria y trayectorias de vida intentamos recuperar y compartir, y es el objetivo de nuestros encuentros.

Bajo un mandato y una sociedad patriarcales, muchas arqueólogas o mujeres que practicaban la arqueología en los cincuenta y sesenta, por ejemplo, al estar la academia dominada por hombres, fueron invisibilizadas de la historia de las investigaciones en nuestro país.

Trabajos iniciales sobre las prácticas androcéntricas mismas y cómo ellas definen desde el campo las perspectivas de la mujer sometida a la mirada del varón fueron planteadas por Gero (1996) y respondidas por Politis (2001), experiencia que no se replicó, ahondó o continuó por no llevar a ningún lugar claro, ya que metodológicamente no era muy rigurosa y estaba mediada también por otras prácticas de poder, como las que se ejercen desde los países centrales a los periféricos. Pero sí notamos tres puntos interesantes para profundizar en futuras investigaciones:

Uno es que las primeras intervenciones explícitamente dedicadas al estudio de las mujeres en nuestra disciplina, ya sea en cuanto al rol de las mujeres en el pasado o en cuanto al presente de las mujeres trabajadoras, estuvo directamente relacionado a investigadoras que, o bien vivían en el exterior o bien tenían redes muy directas en ese momento con feministas del exterior (básicamente, del mundo anglosajón).

El segundo es que, por el contrario, al día de hoy, la enorme cantidad de mujeres y de colectivos de mujeres que hay en el tema y en la disciplina, tienen más que ver con el impacto del feminismo argentino en general a partir de los movimientos Ni una Menos y de los Encuentros Nacionales de Mujeres. Vemos una originalidad en los modos de organización y de discusión, así como de algunas temáticas, respecto a lo que se discute en los países centrales. 
El tercero es que, aun así, con esta multitudinaria apertura y adhesión, hay un modo marcadamente distinto en el modo de ver el pasado, nuestras prácticas y nuestros límites al patriarcado entre las generaciones de las mayores y las más jóvenes. Es de esperar que esta particularidad de los encuentros "El pasado nos convoca", de juntar a discutir especialmente a todas las generaciones, nos ayude a comprender mejor la problemática que nos preocupa y en la cual estamos sumergidas.

Sabemos que el patriarcado goza de buena salud, por lo que los reclamos de las mujeres desde cada espacio y perspectiva son nuestros reclamos, como grupo organizador de este pasado convocante de mujeres arqueólogas argentinas.

\section{In memoriam}

Por último, en cada encuentro hemos recordado a nuestras compañeras que ya no están, y que se van yendo año a año; lo hemos realizado en pequeñas ceremonias cuidadas, compartiendo con alegría, tristeza y discreción, recordando algún aspecto más personal de sus vidas y de sus trayectorias académicas. In memoriam de los encuentros, por sus aportes a la arqueología y su amistad y generosidad, María Ester Albeck, Lidia Baldini, Marta Baldini, Patricia Escola, Ana María Lorandi, Marina Marchegiani, Eleonora Mulvany y Marta Ortiz Malmierca (Boñi).

\section{REFERENCIAS}

Alberti, B. y V. I. Williams.

2005. Introducción. En Williams, V. y B. Alberti (eds.) Género y Etnicidad en la arqueología sudamericana: 7-19. Serie Técnica Nro 4. INCUAPA. UNICEN. Olavarría.

Bellelli, C., M. Berón y V. Scheinsohn.

1993. Una arqueología de distinto género. Publicar 2 (3):47-61.

Bregante, O.

1926. Ensayo de clasificación de la cerámica del Noroeste argentino. Estrada. Buenos Aires.

Chaparro, G., C. Bellelli, V. Scheinsohn y M. Berón.

2019. Género en la arqueología argentina. Trayectorias, prácticas y saberes: Conversatorio 2019. Revista Práctica Arqueológica 2 (1): 42-46.
Conkey, $\mathrm{M}$.

2005. Dwelling at the margins, action at the intersection? Feminist and indigenous archaeologies. Archaeologies. Journal of the World Archaeological Congress 1 (1): 9-59.

Conkey, M. W. y J. D. Spector.

1984. Archaeology and the study of gender. Advances in Archaeological Method and Theory 7: 1-38.

Dillenius, J.

1913 [1911]. Craneometría comparativa de La Isla y el Pukara de Tilcara (Provincia de Jujuy). Tesis para el doctorado en Filosofía y Letras, Universidad de Buenos Aires. Coni Hermanos (ed.).

Duran, M. A.

2008. La ciudad compartida. Conocimiento, afecto y uso. Ediciones SUR. Santiago de Chile. 
Gero, J.

1994. Excavation bias and the women at home ideology. En Nelson, M., S. Nelson y A. Wylie (eds.) Equity issues for women in archaeology: 37-42. Washington. American Anthropological Association AP3A.

Gero, J.

1996. Archaeological practice and gendered encounters with field data. En Wright, R. (ed.) Gender and Archaeology: 251-280. University of Pennsylvania Press. Philadelphia.

Korstanje, M. A.

2005. Comment on "Dwelling at the margins, action at the intersection? Feminist and indigenous archaeologies, 2005". Archaeologies. Journal of the World Archaeological Congress 1 (1): 71-74.

Korstanje, M. A.

Julio 2019. El pasado nos convocó (y tres generaciones de "arqueólogas formadas por mujeres en el NOA" nos reunimos a hablar de nosotras). Ponencia presentada en Género en Arqueología Argentina: trayectorias, prácticas y saberes. Conversatorio del XX Congreso Nacional de Arqueología Argentina: 50 años de arqueologías. Universidad Nacional de Córdoba.

Korstanje, M. A y S. Archila.

2020. Women in South American Archaeology. En Aldenderfer, M., M. Sepulveda y E. Neves (eds.) Handbook of South American Archaeology. Oxford University Press. En prensa.

Lazzari, M.

2003. Archaeological visions. Gender, landscape and optic knowledge. Journal of Social Archaeology 3 (2): 194-222.

Navarrete, $R$.

2010. Excavando mujeres en y desde el sur: Aproximaciones a la arqueología feminista en Latinoamérica. Revista Venezolana de Estudios de la Mujer 15 (34).
Politis, G.

2001. On archaeological praxis, gender bias and indigenous peoples in South America. Journal of Social Archaeology 1(1): 90-107.

Ramundo, P.

2017. Mujeres y arqueología. El aporte de Juliane Dillenius a la historia disciplinar, a través del análisis documental en el Instituto IberoAmericano de Berlín. Actas de las III Jornadas de Investigación y reflexión sobre historia, mujeres y archivos: 151-158. Unicen. Tandil.

Ramundo, $\mathrm{P}$.

2019. La ciencia en manos femeninas: biografía de Juliane Dillenius, la primera antropóloga física americana. Bérose Encyclopédie internationale des histoires de l'anthropologie, Paris. Disponible en: https://www.berose.fr/article1741.html?lang $=\mathrm{fr}$

Scattolin, C.

2003. Representaciones sexuadas y jerarquías sociales en el Noroeste argentino prehispánico. Acta Americana 11(1): 30-48.

Scattolin, C.

2006 a. La mujer que carga el cántaro. En Williams, V. y B. Alberti (eds.) Género y etnicidad en la arqueología de Sudamérica: 43-72. Ediciones Incuapa. Olavarría.

Scattolin, C.

2006 b. Contornos y confines del universo iconográfico Precalchaquí del valle de Santa María. Estudios Atacameños. Arqueología y Antropología Surandinas 32: 119-139. http://dx.doi.org/10.4067/S0718-104320060 00200009.

Williams, V. y B. Alberti (eds.).

2005. Género y etnicidad en la arqueología sudamericana. Serie Teórica 4. INCUAPA, UNICEN. Olavarría.

Wylie, A.

2001. Doing social science as a feminist: The engendering of Archaeology. En Creager, A., E. Lunbeck y L. Schiebinger (eds.) Feminism in twentieth century science, technology, and medicine: 23-45. Chicago UP.

\footnotetext{
${ }^{1}$ Decía: "Yo no sé si llamarlas así, en realidad. No son estudios arqueológicos solamente, tienen su propia ontología de larga data bajo el nombre de estudios indigenistas, dentro de los cuales se incorporan conceptos y materiales que nosotros clasificaremos como arqueológicos. Nos preceden en tiempo y experiencia a los
} 
arqueólogos de la academia, aunque no sean publicados (pauta de la ciencia occidental)" (Korstanje, 2005; texto original en castellano, antes de la traducción al inglés).

${ }^{2}$ Colegio de Graduados en Antropología de la República Argentina, https://www.cgantropologia.org.ar/ciclo-deencuentros-trayectorias/

${ }^{3}$ Hace referencia a las viejas fichas de latón de los teléfonos públicos que, al caer, permitían comenzar el diálogo telefónico.

${ }^{4}$ Conseguimos varios avales institucionales (CONICET, ISES, IAM, IDECU, Departamento de Antropología de la UBA, Fundación Tiempos), pero solo auspiciaron económicamente el evento la Asociación Cooperadora de la Facultad de Ciencias Naturales e IML y la Caja Popular de Ahorros de Tucumán, a quienes les estamos muy agradecidas.

${ }^{5}$ Cuando la pandemia (COVID-19) lo permita. 